\title{
Effect of Atorvastatin in Radiographic Density on Alveolar Bone Loss in Wistar Rats
}

\author{
Paula GOES ${ }^{1}$ \\ Ana Patrícia Souza LIMA ${ }^{1}$ \\ Iracema Matos MELO ${ }^{1}$ \\ Rodrigo Otávio Citó César RÊGO² \\ Vilma LIMA $^{3}$ \\ ${ }^{1}$ Department of Clinical Dentistry, Dental School, Federal University of Ceará, Fortaleza, CE, Brazil \\ ${ }^{2}$ Department of Periodontics, Dental School, Federal University of Ceará, Sobral, CE, Brazil \\ ${ }^{3}$ Department of Physiology and Pharmacology, Medical School, Federal University of Ceará, Fortaleza, CE, Brazil
}

\begin{abstract}
The purpose of this study was to evaluate the effect of Atorvastatin (ATV) on alveolar bone loss induced in rats. Periodontitis was induced by ligature placement around the upper second left molar in a total of 24 male Wistar rats $( \pm 200$ g). Groups of 6 animals received via oral gavage either saline or ATV $(1,3$ and $9 \mathrm{mg} / \mathrm{kg})$ during 11 days. After this time, the animals were sacrificed and their maxillae were removed, defleshed, radiographed by Digora System ${ }^{\circledR}$, and latter stained to be photographed using a digital camera. Data were analyzed statistically by ANOVA and Bonferroni test at 5\% significance level and presented as mean \pm SEM. ATV ( 9 mg/ $\mathrm{kg}$ ) caused a significant increase on gray tone variation of over $48 \%(118.3 \pm 12.0$ gray tones) when compared to saline (79.8 \pm 6.2 gray tones), indicating greater radiographic density. These data were corroborated by macroscopic findings, where ATV (9 mg/kg) reduced alveolar bone loss by over $47 \%(\mathrm{p}<0.05)$, when compared to the group of untreated animals (saline). In summary, ATV was able to prevent alveolar bone loss seen on a ligature-induced periodontitis model.
\end{abstract}

Key Words: Atorvastatin, periodontitis, radiography, bone density, rats.

\section{INTRODUCTION}

Bone tissue undergoes continuous remodeling through repeated cycles of destruction and renovation, mediated by the well balanced actions of osteoclasts, and osteoblasts. Bone homeostasis can be unbalanced by pathological processes, allowing resorptive events overlapping the formative ones, resulting in loss of bone structure. Periodontitis is characterized by inflammatory response and alveolar bone loss, where chemical mediators, such as cytokines, prostaglandins, matrix metalloproteinases, have been identified as immunoinflammatory process regulators (1). Periodontal disease is among one of oral problems that most extensively affect human population, being one of the major causes for adult tooth loss.

Different approaches have been used to treat periodontal diseases. Mechanical therapy, such as scaling and root planning and surgical procedures, reduce microbial burden, being effective on the control of periodontitis progression. Nevertheless, this regulation is not always satisfactory, possibly due to the prominent role of immune response on periodontal destruction and, adjunctive therapies may be required in some cases (2).

Statins gather a class of agents, which inhibit hydroxymethylglutaryl coenzyme A (HMG-CoA) reductase enzyme, leading to management of cholesterol production. Atorvastatin (ATV), an inhibitor of HMGCoA reductase enzyme, has been widely used on clinical practice in order to prevent cardiovascular accidents (3). Apart from their hypolipemiant function, statins have stood out by their additional secondary effects, including antiinflammatory, immunomodulatory, antioxidant, antithrombotic and endothelium stabilization actions (4), as well as angiogenesis promotion and increase of osteoblastic differentiation, inducing bone formation (5).

The determination of the efficacy of periodontal therapy (either mechanical or chemical) is based on

Correspondence: Profa. Dra. Vilma Lima, Departamento de Fisiologia e Farmacologia, Laboratório de Farmacologia Oral, Universidade Federal do Ceará, Rua Coronel Nunes de Melo, 1127, Rodolfo Teófilo, 60420-270 Fortaleza, CE, Brasil. e-mail: villima@yahoo.com.br ou vilma@ufc.br 
the maintenance or recovery of alveolar support. Generally, the evaluation of a successful therapy in periodontal patients is done by clinical probing associated with radiographic images. The main objective of the radiographic assessment lies on the recognition of any quantitative bone alteration, which is very important to periodontology, since periodontitis has a slow progression, causing slight loss of structure in periodontal scaffold (6).

Conventional radiography, the most widely used complementary exam in dentistry, presents some limitations due to low sensibility and high inter-examiner disagreement. Currently, digital images have taken over a notability position. These images have the ability to detect discrete bone loss, and provide an objective analysis, allowing a wide variety of manipulation and quantification tools, and gray tone determination (7). These characteristics are of particular interest for periodontal disease evaluation.

Rat models have been largely used to study periodontitis progression, due to the anatomical and histological similarities to those of humans. A fast and easy method to induce periodontitis consists on ligature placement around the molar, which causes an unspecific inflammatory process $(8,9)$. In this way, the aim of this study was to evaluate the effect of ATV on ligatureinduced alveolar bone loss in rats, by radiographic density and morphometric analyses.

\section{MATERIAL AND METHODS}

\section{Animal Selection}

Twenty-four 5-week-old male Wistar rats (Rattus norvegicus), from our own animal facilities, were used in this study. The animals were acclimatized for at least 1 week before the start of the experiment, and were housed under normal laboratory conditions with laboratory chow and water available ad libitum. Experimental protocols were executed following ethical principles for laboratory animal use, as approved by the institutional Ethical Committee of Animal Research (Process No. 74/2007). All efforts were made to reduce animal number, their pain, suffering and stress.

\section{Experimental Periodontitis Model}

For the study, the rats were divided into 4 groups, with 6 animals each (8). The model of ligature-induced periodontitis used was based on Lima et al. (8), which consists on the insertion of a nylon ligature around the cervix of the upper left second molar of rats anesthetized with chloral hydrate (Vetec Química Fina Ltda., Duque de Caxias, RJ, Brazil). Ligature was placed through proximal space of the referred tooth, and was knotted on buccal side of the tooth, resulting in a subgingival position palatally and in a supragingival position buccally. The contralateral right side was used as the unligated control. Animals were observed until the 11th day, when they presented the most intense alveolar bone loss (9) and were then sacrificed. The animals were allocated randomly in each group considering just their body mass, and the operator was blinded to which group each animal belonged to.

\section{Groups}

Saline Group: This control group was constituted by 6 rats subjected to experimentally induced periodontitis. The animals received $0.5 \mathrm{~mL}$ of sterile saline by oral gavage (v.o.), $30 \mathrm{~min}$ before ligature placement and then daily, during 11 days. At the 11th day, the animals were sacrificed.

ATV Groups: The other 18 rats were subdivided in 3 groups of 6 animals each, which received ATV (Lipitor $^{\circledR}$, Pfizer, São Paulo, SP, Brazil) dissolved in sterile saline by oral gavage (v.o.) at doses of 1, 3 and $9 \mathrm{mg} / \mathrm{kg}$, for each respective group. These doses were chosen in agreement with other studies, which showed that similar doses were effective to reduce inflammation or nociception (10). ATV was administered 30 min before ligature placement and then daily, during 11 days, when the animals were sacrificed.

\section{Local Parameters Evaluated on Experimental Periodontitis}

Analysis of Radiographic Density: On the 11th day after periodontitis induction, the animals were sacrificed and their maxillae were removed and fixed for $24 \mathrm{~h}$ in $10 \%$ formaldehyde (Reagen, Rio de Janeiro, RJ, Brazil), and the maxillae were then bisected and defleshed $(8,9)$. After that, the specimens had their radiographic density analyzed by digital radiography using Digora Soredex System $^{\circledR}$ (Dental Imaging Company Ltd, PortsladeEast Sussex, UK). The hemi-maxillae were posed over the sensor. Radiographic images were acquired using $63 \mathrm{kVp}, 8 \mathrm{~mA}, 0.06 \mathrm{~s}$ time exposure and $30 \mathrm{~cm}$ focal 
distance. These images were evaluated by Image J $1.31 \mathrm{p}$ software (ImageJ 1.32j, National Institute of Health, USA

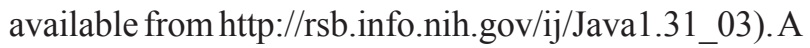
128 pixel interest region was selected and posed under the cementoenamel junction from mesial to distal area of second molar in the diseased side as well as on its contra lateral normal side. Gray tone differences from both areas were considered as a value of radiographic density. Interest region (IR) radiographic density analysis was done by the histogram tool of Image J software, which uses a 256 gray tone scale, where zero indicates the black color and 255 the white one. Data were expressed in arbitrary gray tones (7).

Morphometric study of bone tissue: The same specimens used for radiographic analysis were subjected to macroscopic bone resorption quantification. Both hemi-maxillae were stained with aqueous $1 \%$ methylene blue (Vetec Química Fina Ltda.), placed on glass slices and photographed using a digital camera (Nikon D40, Melville, NY, USA). Alveolar bone loss quantification was evaluated by Image J software. Resorption area calculation was done by delimited region, involving occlusal border of vestibular side of the teeth until bone border based on Kurh et al. (11), with some modifications. The obtained area of challenged hemimaxilla (Fig. 1B) was subtracted from the respective area of the normal contra lateral hemi-maxilla (Fig. 1A). Acquired images were compared to a well-known area $\left(0.25 \mathrm{~mm}^{2}\right)$ in order to convert pixels to $\mathrm{mm}^{2}$.

\section{Statistical Analysis}

Results were expressed as mean \pm standard error of the mean (SEM), and were analyzed by ANOVA and Bonferroni's correction test. A $p<0.05$ value was considered as indicating significant differences.

\section{RESULTS}

Table 1 shows the results of the radiographic density analysis determined by gray tones. Radiographs of non-treated animals subjected to periodontitis (saline group) showed intense alveolar bone resorption $(\mathrm{p}<0.05)$, when compared control side (contra-lateral hemi-maxilla). Although low doses of ATV showed a tendency to reduce bone loss ( $>00.05$ ), only ATV $9 \mathrm{mg}$ / kg exhibited significant gray tone increase, over $48 \%$ on gray tone variation, indicating bone preservation after
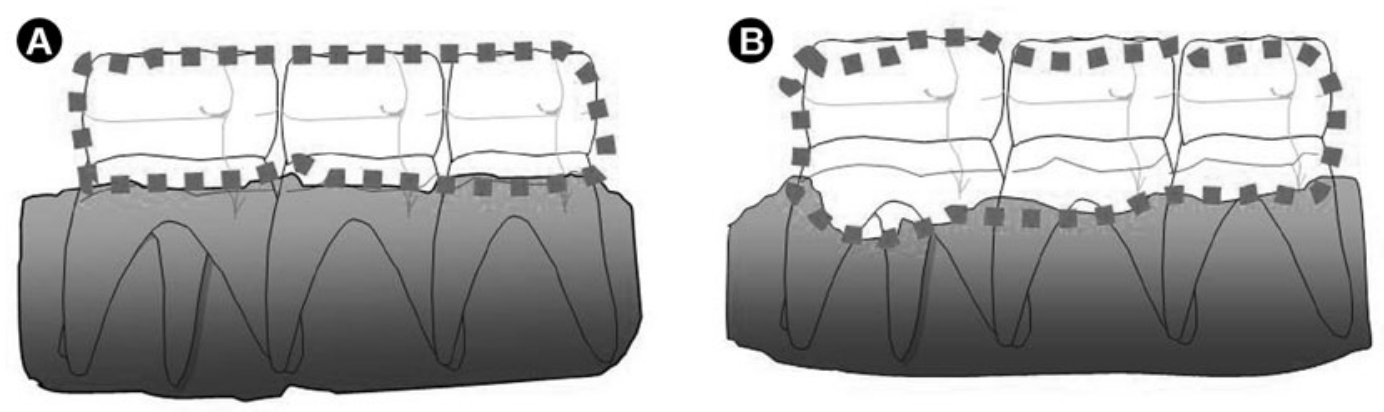

Figure 1. Schematic presentation of the area calculation of bone resorption. A) normal hemi-maxilla; B) hemi-maxilla subjected to ligature-induced periodontitis.

Table 1. Radiographic and macroscopic analyses of normal hemi-maxillae (HM) and HM subjected to periodontitis in animals receiving either saline (control) or ATV. Data are presented as the mean \pm SEM of 6 rats for each group by ANOVA and Bonferroni's test.

\begin{tabular}{|c|c|c|c|c|c|}
\hline \multirow{2}{*}{$\begin{array}{l}\text { Groups } \\
\text { (analysis method) }\end{array}$} & \multicolumn{2}{|c|}{ Saline } & \multicolumn{3}{|c|}{ Treatment } \\
\hline & Normal HM & Diseased HM & ATV $1(\mathrm{mg} / \mathrm{kg})$ & ATV 3 (mg/kg) & ATV $9(\mathrm{mg} / \mathrm{kg})$ \\
\hline $\mathrm{RD}$ (gray tone) & $189.1 \pm 3.4^{*}$ & $79.8 \pm 6.2$ & $90.3 \pm 10.5$ & $96.8 \pm 7.6$ & $118.3 \pm 12.0^{*}$ \\
\hline $\mathrm{ABR}\left(\mathrm{mm}^{2}\right)$ & $0.0 \pm 0.0$ & $3.9 \pm 0.3$ & $3.0 \pm 0.3$ & $3.0 \pm 0.2$ & $2.3 \pm 0.2 *$ \\
\hline
\end{tabular}

*Statistically significant difference compared to saline group $(\mathrm{p}<0.05) . \mathrm{RD}=$ radiographic density, $\mathrm{ABR}=$ alveolar bone resorption. 
ligature-induced periodontitis.

Macroscopic analysis of alveolar bone resorption of animals subjected to periodontitis can be seen on Table 1. It was verified that 11 days of ligature caused intense alveolar bone resorption on the saline group $(\mathrm{p}<0.05)$. On the other hand, it was noted the protective effect of ATV on alveolar bone tissue of animals subjected to periodontitis. Although low doses of ATV ( 1 or 3 $\mathrm{mg} / \mathrm{kg}$ ) presented a non-significant tendency to bone protection, ATV highest dose $(9 \mathrm{mg} / \mathrm{kg})$ was able to reduce alveolar bone loss over $47 \%$ when compared to saline $(\mathrm{p}<0.05)$. Thus, macroscopic data corroborate radiographic findings, since both analyses had been correlated to each other in an indirectly proportional manner.

Radiographic and macroscopic images are presented in Figures 2 and 3, respectively. Figures $2 \mathrm{~B}$ and $3 \mathrm{~B}$ indicate radiographic and macroscopic aspects, respectively, of a non-treated hemi-maxilla after 11 days of ligature-induced periodontitis (saline). It can be seen that second molar region presents loss of bone tissue, associated to bone loss in furcation area (Fig. 2B). Macroscopically, an intense alveolar bone destruction, root and furcation area exposure is observed (Fig. 3B). These images are extremely different when

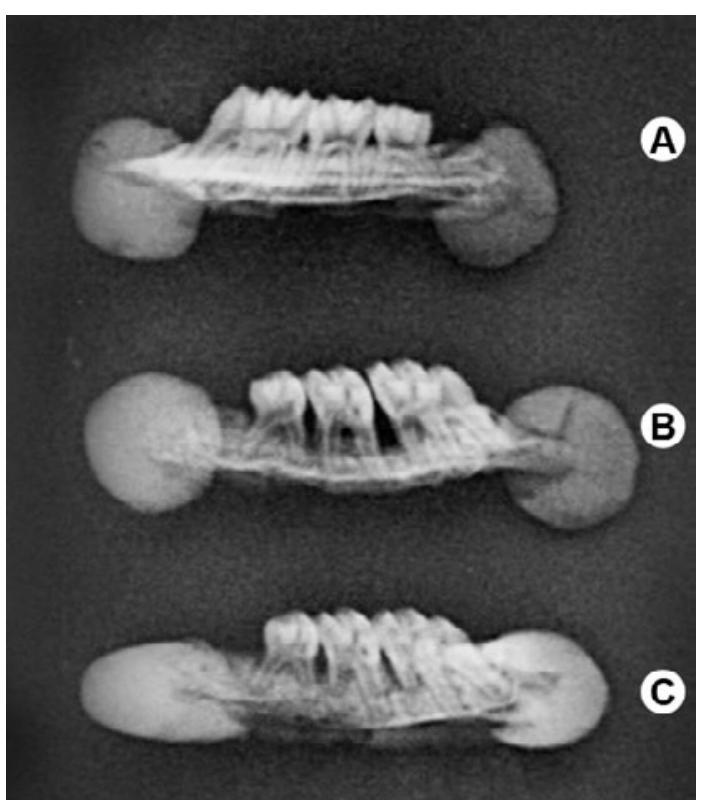

Figure 2. Radiographic aspect of rat hemi-maxillae: A) Radiograph of normal hemi-maxilla; B) Radiograph of diseased hemi-maxilla of rat that received saline; $\mathrm{C}$ ) Radiograph of diseased hemi-maxilla of rat treated with ATV $(9 \mathrm{mg} / \mathrm{kg})$. compared to normal hemi-maxilla. Periodontal structure was preserved in both radiographic (Fig. 2A) and macroscopic (Fig. 3A) analyses. In order to illustrate the protective effect of ATV $(9 \mathrm{mg} / \mathrm{kg}$ ), Figure $2 \mathrm{C}$ shows its radiographic appearance, indicating alveolar crest preservation and lower bone loss in furcation area as well as in proximal faces of upper second molar, corroborated by macroscopic aspect of alveolar bone, which were also well preserved (Fig. 3C).

\section{DISCUSSION}

Periodontitis is related to several inflammatory mediators, which contribute not only to bone homeostasis, but also to tissue destruction. Considering that local bone loss is an immunoinflammatory exacerbated reaction and localized osteoclastogenesis combination (11), ligature-induced alveolar bone loss occurs due to abnormal activation of host immunological system with consequent uncontrolled inflammatory response (12).

Inflammatory mediators, such as TNF, IL-1 and IL-6, induce receptor activator of nuclear- $\mathrm{\kappa B}$. Factor (RANK) and its ligant (RANKL) inducing osteoclastic differentiation and maturation, promoting bone environment unbalance and hard tissue resorption. Many

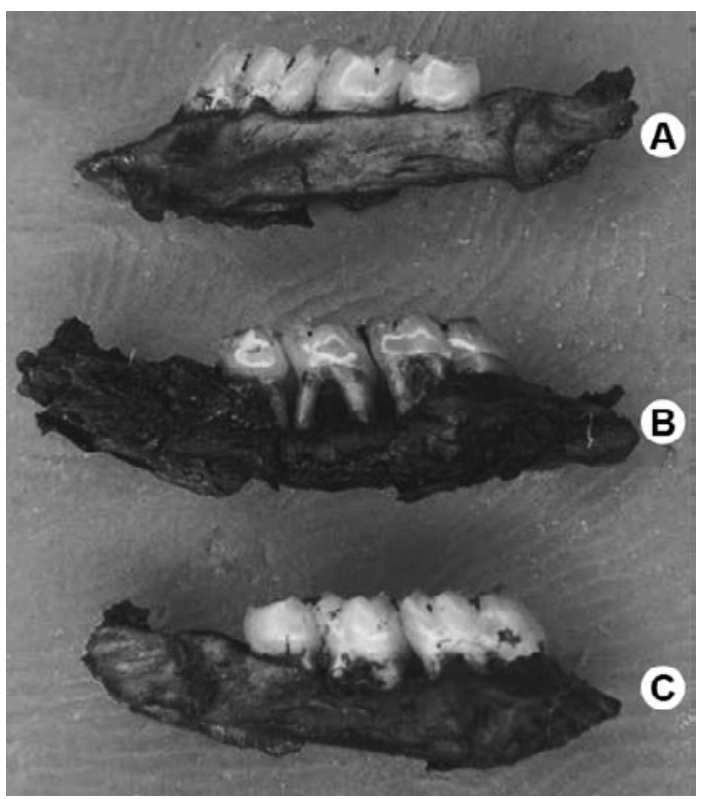

Figure 3. Macroscopic aspect of rat hemi-maxillae: A) Photograph of normal hemi-maxilla; B) Photograph of diseased hemi-maxillae of rat that received saline; C) Photograph of diseased hemi-maxilla of rat treated with ATV $(9 \mathrm{mg} / \mathrm{kg}$ ) (Original magnification $7 \times)$. 
other osteoclast activator factors such as, transforming growth factor (TGF)- $\beta$, macrophage-colony stimulator factor (M-CSF), hepatocytes growth factor (HGF), matrix metalloproteinases (MMPs), macrophage inflammatory protein (MIP)- $1 \alpha$, have been identified on periodontal disease (12).

In this context, ATV stands out because it may act in important steps during exacerbated inflammatory response. It has been described that statins decrease the production of many proinflammatory cytokines, down regulating interleukin- $1 \alpha$-induced IL- 6 and IL-8 production in epithelial cells in a dose-dependent manner (13). Moreover, statins have been found to decrease secretion of MMP-1, MMP-2, MMP-3 and MMP-9 in vitro (14). Thus, statins may dampen the fierce immune response, protecting periodontal tissue against destruction, possibly via some of the above-mentioned antiinflammatory mechanisms (15).

On the other hand, ATV has the ability to induce bone anabolism as it was reported bone morphogenetic protein-2 (BMP-2) increased expression in rat calvaria treated with statins, improving tibia trabecular bone volume (16). Some clinical trials using none-specific alkaline phosphatase (BALP) as bone formation marker, confirmed bone mineral density (BMD) improvement in osteoporic women after ATV therapy (17).

Although the antiinflammatory mechanisms of ATV are not yet fully understood, it is recognized that ATV has important clinical benefits in inflammatory disorders, such as periodontal disease $(15,18,19)$, interfering consequently, on bone resorptive process. Several authors have reported the successful use of ATV on periodontitis, by reducing tooth loss in patients with chronic periodontitis (18), exhibiting fewer signs of inflammatory injury (19). Therefore, it may be inferred that ATV antiinflammatory action and bone anabolism characteristic must be considered on alveolar bone protection, seen in this study.

In order to evaluate periodontal condition, several assays have used conventional radiographic images, due to the obvious bone alterations seen (20). However, when bone anabolic events are still subtle, conventional biochemical and radiographic markers are not always sensitive enough to reveal such changes. This way, digital radiographic images present an additional vantage, as they demonstrate capacity to reveal larger number of early sites with bone loss (20). Considering that radiographic analysis evidenced the protective effect of ATV in the bone loss, as well as the macroscopic analysis, it is supposed that digital images can be a quite reliable tool in situations where the bone loss are subtle, as observed in this animal model.

In summary, ATV promoted alveolar bone protection in ligature-induced periodontitis in rats. Further studies should be performed to confirm these results.

\section{RESUMO}

O objetivo deste estudo foi avaliar o efeito da Atorvastatina (ATV) na perda óssea alveolar induzida em ratos. A periodontite foi induzida através da colocação de ligadura ao redor do segundo molar superior esquerdo de um total de 24 ratos Wistar machos ( \pm $200 \mathrm{~g}$ ). Grupos de 6 animais receberam por via oral solução Salina a $0,9 \%$ ou Atorvastatina $(1,3$ e $9 \mathrm{mg} / \mathrm{kg})$, por 11 dias, quando então foram sacrificados e suas maxilas foram removidas, dissecadas, radiografadas através do Sistema Digora System ${ }^{\circledR}$, e fotografados usando câmara digital. Os dados foram expressos como média \pm EPM (ANOVA e teste de Bonferroni). Atorvastatina ( $9 \mathrm{mg}$ / $\mathrm{kg}$ ) causou aumento significante de aproximadamente $48 \%$ na variação de tons de cinza (ATV 9=118,3 $\pm 12,0$ tons de cinza), indicando maior densidade radiográfica, quando comparada ao controle (solução salina $=79,8 \pm 6,2$ tons de cinza). Estes dados foram corroborados pelos achados macroscópicos, onde Atorvastatina $(9 \mathrm{mg} / \mathrm{kg}$ ) reduziu a perda óssea alveolar em $47 \%$ $(\mathrm{p}<0,05)$, quando comparado aos animais não tratados (solução salina). Em suma, a Atorvastatina preveniu a perda óssea alveolar vista no modelo de periodontite induzida por ligadura.

\section{ACKNOWLEDGEMENTS}

The authors gratefully acknowledge "Clínica Perboyre Castelo-Radiologia Odontológica” for digital radiographic registration. This work was supported by the Ceará State Foundation of Technological and Scientific Development (FUNCAP) and the National Coucil of Technological and Scientific Development (CNPq).

\section{REFERENCES}

1. Ishikawa I. Host responses in periodontal diseases: a preview. Periodontol 2000 2007;43:9-13.

2. Buduneli E, Vardar-Sengül S, Buduneli N, Atilla G, Wahlgren J, Sorsa T. Matrix metalloproteinase, tissue inhibitor of MMP-1 and laminin-5 $\gamma 2$ chain immunolocalization in gingival tissue of endotoxin-induced periodontitis in rats: effects of low-dose doxycyline and alendronate. J Periodontol 2007;78:127-134.

3. LaRosa JC, Grundy SM, Kastelein JJ, Kostis JB, Greten H. Treating to New Targets (TNT) Steering Committee and Investigators. Safety and efficacy of Atorvastatin-induced very low-density lipoprotein cholesterol levels in Patients with coronary heart disease (a post hoc analysis of the treating to new targets [TNT] study). Am J Cardiol 2007;100:747-752.

4. Landmesser U, Bahlmann F, Mueller M, Spiekermann S, 
Kirchhoff N, Schulz S, et al.. Simvastatin versus ezetimibe: pleiotropic and lipid-lowering effects on endothelial function in humans. Circulation 2005;111:2356-2363.

5. Maeda T, Matsunuma A, Kurahashi I, Yanagawa T, Yoshida H, Horiuchi N. Induction of osteoblast differentiation indices by statins in MC3T3-E1 cells. J Cell Biochem 2004;92:458-471.

6. Hausmann E. Radiographic and digital imaging in periodontal practice. J Periodontol 2000;71:497-503.

7. Anbinder AL, Prado Fde A, Prado Mde A, Balducci I, Rocha RF. The influence of ovariectomy, simvastatin and sodium alendronate on alveolar bone in rats. Braz Oral Res 2007;21:247-252.

8. Lima V, Vidal FDP, Rocha FAC, Brito GAC, Ribeiro RA. Effects of TNF- $\alpha$ inhibitors pentoxifylline and thalidomide on alveolar bone loss in short-term experimental periodontal disease in rats. J Periodontol 2004;75:162-168.

9. Lima V, Bezerra MM, Alencar VBM, Vidal FDP, Rocha FAC, Brito GAC, et al.. Effects of chlorpromazine on alveolar bone loss in experimental periodontal disease in rats. Eur J Oral Sci 2000;108:123-129.

10. Barsante MM, Roffê E, Yokoro CM, Tafuri WL, Souza DG, Pinho $\mathrm{V}$, et al.. Anti-inflammatory and analgesic effects of atorvastatin in a rat model of adjuvant-induced arthritis. Eur J Pharmacol 2005;516:282-289.

11. Kuhr A, Popa-Wagner A, Schmoll H, Schwahn C, Kocher T. Observations on experimental marginal periodontitis in rats. J Periodontal Res 2004;39:101-106.

12. Takayanagi H. Inflammatory bone destruction and osteoimmunology. J Periodont Res 2005;40:287-293.

13. Sakoda K, Yamamoto M, Negishi Y, Liao JK, Node K, Izumi Y.
Simvastatin decreases IL-6 and IL-8 production in epithelial cells J Dent Res 2006;85:520-523.

14. Luan Z, Chase AJ, Newby AC. Statins inhibit secretion of metalloproteinases-1, $-2,-3$, and -9 from vascular smooth muscle cells and macrophages. Arterioscler Thromb Vasc Biol 2003;23:769-775.

15. Saxlin T, Suominen-Taipale L, Knuuttila M, Alha P, Ylöstalo P. Dual effect of statin medication on the periodontium. J Clin Periodontol. 2009;36:997-1003.

16. Mundy G, Garrett R, Harris S, Chan J, Chen D, Rossini G, et al.. Stimulation of bone formation in vitro and in rodents by statins. Science 1999;286:1946-1949.

17. Tanriverdi HA, Barut A, Sarikaya S. Statins have additive effects to vertebral bone mineral density in combination with risidronate in hypercholesterolemic postmenopausal women. Eur J Obst Gynecol Reprod Bio 2005;120:63-68.

18. Cunha-Cruz J, Saver B, Maupome G, Hujoel PP. Statin use and tooth loss in chronic periodontitis patients. J Periodontol 2006;77:1061-1066.

19. Lindy O, Suomalainen K, Mäkelä M, Lindy S. Statin use is associated with fewer periodontal lesions: A retrospective study. BMC Oral Health 2008;15:8-16.

20. Anbinder AL, Prado Mde A, Spalding M, Balducci I, Carvalho YR, da Rocha RF. Estrogen deficiency and periodontal condition in rats: a radiographic and macroscopic study. Braz Dent J 2006; 17:201-207.

Accepted June 11, 2010 